\title{
Regional, continental, and global mobility to an emerging economy: the case of South Africa
}

\author{
Jenny J. Lee $\cdot$ Chika Sehoole \\ J. J. Lee (correspondence author) \\ University of Arizona, Tucson, AZ, USA \\ e-mail: jennylee@u.arizona.edu; JennyLee@arizona.edu \\ J. J. Lee \\ Korea University, Seoul, South Korea \\ C. Sehoole \\ University of Pretoria, Pretoria, South Africa \\ e-mail: chika.sehoole@up.ac.za
}

\begin{abstract}
This study examined mobility within the understudied region of southern Africa and particularly, the factors that drive and shape educational migration toward South Africa as a regional, continental, and global destination. Based on a survey admi-nistered to international students across seven South African universities, the findings revealed leading reasons were based on human capital and geopolitical rationales. The study also uncovered notable differences based on students' geographic origins.
\end{abstract}

Keywords International students · International mobility · South Africa · Regional hub

\section{Introduction}

Educational migration is at an all-time high. The 2012 figures indicate that close to 4.5 million students were enrolled in institutions outside their country of citizenship, more than double than in 2000, with an annual growth rate of $7 \%$ (Organization for Economic Cooperation and Development [OECD], 2014). For some time, the predominant destinations of educational migrants have been English-speaking and western European countries, the top five of these being the US, the UK, Australia, Germany, and France, which accounted for about $50 \%$ of the world's students in 2012. Yet these countries' global proportion of international students has declined somewhat as interest has increased in studying abroad in less developed parts of the world (OECD 2014). That fact makes this 
study, which focuses on South Africa as one of the emerging educational destinations in Southern Africa as well as globally, particularly relevant.

Although more scholarly attention is paid to global mobility than regional mobility, a significant proportion of international education occurs across shared borders throughout the world. Among all OECD countries, $21 \%$ of international students study in countries sharing a direct land or maritime border with their homeland (OECD 2014). Such border patterns have been generally observed within western and eastern Europe, East Asia, Latin America, and southern Africa (OECD 2014). Despite this prevalence, far less investigation exists on regional hubs, particularly among emerging economies. A 2014 report on global connectedness found that emerging economies participate in the majority of international interactions and that the top ten countries with the greatest increases in global connectedness from 2011 to 2013 were all emerging economies (Ghemawat and Altman 2014). These emerging economies are arguably strong regional as well as emerging global players.

Despite being the largest continent in the world, there is especially limited empirical higher education research that is published on Africa. In terms of mobility, Africa is commonly viewed as a major sufferer of brain drain, losing its highly skilled and academic talent to more developed countries in western Europe and North America. Yet what is often overlooked is South Africa's important role in building international human capital by receiving international scholars and students from abroad, particularly from the south of the continent as a regional hub. As shown in Fig. 1, a large majority of its students are from within the region. The country also attracts a fair share of African students from outside its immediate region. With 54 countries comprising the African union, South Africa is also a major destination for many African students further north, despite them being of much closer proximity to Europe and the Middle East. The country is also a popular destination for students from outside the continent. Thus, we sought to investigate mobility within the understudied region of southern Africa and particularly, the factors that drive and shape educational migration toward South Africa as a regional, continental, and global destination.

\section{Rationales for international education}

Migration, including educational migration, has been largely understood as a matter of resources. The traditional push-pull model suggests students are "pushed", out of their home

Fig. 1 Percentage of South African international students' home region. Source: higher education management information system data, (2013), DHET

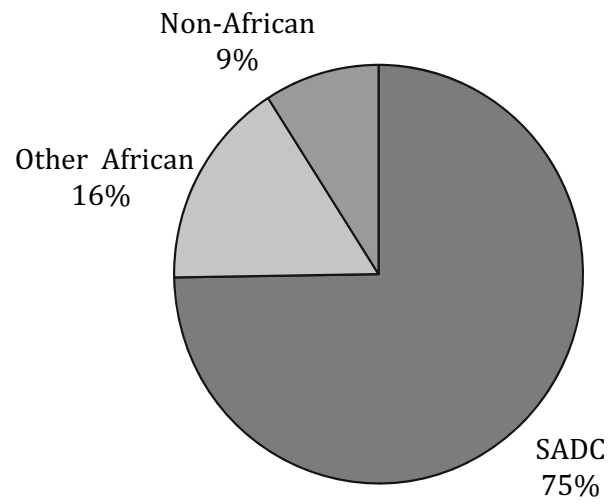


country due to inadequate or inferior educational resources and are "pulled" to a foreign country in order to obtain a better education (Altbach 2004). This widely cited framework has proven useful in explaining global mobility, particularly to the most resourced countries in the West, but does not fully capture the emerging growth of regional mobility taking place in other parts of the world. With such broadening of international destinations, many have worked to draw attention to the role of less-studied countries or regions (e.g., Kondakci 2011; L e e a n d K i m 2010; L i a n d B r a y 2007; McMahon 1992; Sehoole 2011).

This research has major implications for how international higher education is theorized and implemented. In place of the sweeping view that internationalization is unidirectional (from developing to developed countries) and undertaken for a uniform set of rationales, there is a need to further explore educational mobility within regions. The OECD (2014) has, in fact, reported, "The growth in the internationalization of tertiary enrollment in OECD countries, as well as the high proportion of intra-regional student mobility show the growing importance of regional mobility over global mobility.', (p. 346). In other words, more and more students are seeking to study within their own region rather than travel to more distant destinations. This trend is most evident within the European Union, supported by the Erasmus program, followed by the 15 southern African states within the Southern African Development Community (SADC). A United Nations Educational, Scientific and Cultural Organization (2012) report on SADC students indicated that students from Southern Africa are the most mobile students worldwide, with six out of every hundred higher education students studying abroad. However, the data further showed that the better part of that mobility was taking place intra-regionally, with $50 \%$-second only to western Europe, staying in their own region.

There has also been an emerging and significant body of research that differentiates educational migration from the perspective of non-Western and economically developing countries (Cantwell et al. 2009; Kondakci 2011). Previous research has also shown that the motivations for and experiences of those migrating to nearby versus distant countries reportedly differ. Cantwell et al. (2009) were among the first researchers to distinguish how students from different regions had varying orientations toward studying in a developing country. They found that international students from North America and Europe frequently sought short-term international study in Mexico for reasons related to learning about its culture; in contrast, Latin Americans were more oriented toward the intention of obtaining a degree in the country. Kondakci (2011) correspondingly found that students from developing countries chose to study in Turkey, rather than in western countries, for financial and aca-demic quality reasons. Similar findings held true in a case study of international students in South Korea. Jon et al. (2014) identified the country as a major regional destination in East Asia, especially for Chinese students. Students from Asia tended to seek study in Korea, and in a particular host institution there, for economic and utilitarian reasons, whereas students from North America and Europe had different motivations. In sum, these studies suggest that some non-Western and developing countries serve as regional hubs, attracting students from neighboring countries seeking a better quality of education than they could find in their home countries. This research also highlights how rationales for studying in such destinations might differ based on one's geographical origin.

\section{Case of South Africa}

The popularity of South Africa as a leading destination of choice for SADC and other African students makes South Africa a regional and continental hub in higher education 
and a worthwhile case study for the phenomenon of mobility. Like the top global recipients (US, the UK, Australia, Germany, and France), South Africa's inbound rate exceeds its outbound rate (British Council 2012). The role of South Africa as a regional and continental hub and its contribution in human capital development in the region should be understood in the light of its relative strengths compared to other countries in the African continent and the global South. South Africa is a middle-income, emerging market, a fact with particular implications in terms of international migration (Crush et al. 2005). Just over a decade ago, it was reported that two-thirds of highly skilled professionals had considered relocating out of the country since the end of apartheid, due to changes such as declining quality of life (increased cost of living, security and safety concerns, and lower quality of public services; Bhorat et al. 2002). Since that time, however, conditions have improved with an abundant supply of natural resources; well-developed financial, legal, communications, energy, and transport sectors; a stock exchange that is largest in Africa and the 19th largest in the world (World Economic Forum 2014a); and modern infrastructure supporting an efficient distribution of goods to major urban centers throughout the region. Growth was especially robust from 2004 to 2008 as South Africa reaped the benefits of macroeconomic stability and a global commodities' boom and was able to survive the recession of 2008. However, growth started slowing since the second half of 2008 due to the global financial crisis' impact on commodity prices and demand (SAccess 2014) and then dropped more recently as a consequence of "the diversion of public funds, the perceived wastefulness of government spending, and a more general lack of public trust in politicians"' (WEF 2014b, p. 17). Despite such recent setbacks, the country's economy maintains significantly higher strata of development in relation to the rest of the region. South Africa's global competitiveness ranking is at 56th place, making it the second most economically productive country in Sub-Saharan Africa, after Mauritius (WEF 2014a).

Other geopolitical features of the South African context make the country appealing to many Africans. In his study, Kiboiy (2013) showed how student unrests throughout the African continent can be traced to the first generation of African nationalists whose activities were linked to earlier struggles against colonial governments. These protests revolved less around internal educational matters and more around wider global concerns such as foreign policies regarding the politics of the cold war and South Africa's apartheid system (Nkinyangi 1991). Of late, unrests in African higher education are continuing in response to cost cutting and privatization measures in universities (Kiboiy 2013). While such protests may be true in many of African countries, South African higher education system has enjoyed considerable stability since the dawn of democracy in 1994. Even though demonstrations in South African higher education institutions have been observed, which tend to be related to fees, accommodation, or racism, these have been campus specific and have not led to a national strike or boycott of academic activities.

Yet the demand to study abroad in South Africa is greatest in its immediate neighboring countries. Since the SADC 1997 initiative to promote regional cooperation in the educational sector, educational mobility within the region has notably increased and remains a major regional hub. The SADC policy reserves at least $5 \%$ of university slots for students from SADC member countries and set lower tuition fees for SADC students than for nonSADC foreign students (Marko 2009). In terms of numbers, in 2009, some 89,000 SADC students studied outside their home countries and the number accounted for $5.8 \%$ of tertiary enrollment. This ratio is higher than the regional average for Sub-Saharan Africa $(4.9 \%)$ and is three times higher than the world average $(2 \%)$. Nearly half of these 
students go to South Africa, followed by the UK (10\%) and the USA (8\%) (Chien and Kot 2011).

The country is not only a regional hub, but also an emerging global destination. Among students from western nations, studying abroad in countries outside Europe and North America in order to experience diverse cultures has also become increasingly popular. In the USA, for example, South Africa ranks 13th as a preferred study destination (Institute of International Education 2013). Globally, South Africa is 14th as a preferred destination for international students and is the only African country featured in the OECD higher education reporting (2014). Likely reasons for its popularity include its relatively low cost of living and university fees compared to many developed countries, English instruction, and the excellent reputation of many of its institutions in the Sub-Saharan region.

In sum, South Africa is an educational destination regionally, continentally, and globally. The South African university sector is the largest and strongest higher education system in Africa, with 23 public universities across three institutional types: traditional research, comprehensive, and technology universities, to meet a wide range of tertiary education needs, from advanced research to skilled workforce training. Each of these institutional types attracts a high share of Africa's international students, helping to curb the country's brain drain (OECD 2014). As a primary destination of choice for Southern African students, the country is a major regional hub (Sehoole 2011). South Africa plays a dynamic role in the continent as well, contributing to capacity building by training students from other African countries. Based on its popularity outside the continent, it is arguably also a global destination. Its role in educating both Africans and non-Africans makes it a worthwhile case study for the phenomenon of educational migration. South Africa plays critical roles in the continent's human resource development and in helping to retain skilled graduates in Africa (MacGregor 2007), while also educating students from other continents as well. Still lacking, however, are in-depth empirical studies of students who study in South Africa and their reasons for their choice. Such information is vital in improving the country's ability to recruit and educate the world's students as well as understanding international student mobility in this understudied part of the world.

\section{Background}

The Department of Higher Education and Training (DHET) in South Africa, a branch of the country's national ministry of education, provided the background data for the study. Our analysis of the 2013 DHET data revealed that SADC students constituted just $5.5 \%$ of South Africa's higher education enrollment but $74.3 \%$ of the country's international students. The highest senders to South Africa are largely SADC countries, comprising the top eight countries of origin (See Table 1). The top four countries (Zimbabwe, Namibia, Lesotho, and Swaziland) share direct borders with South Africa, with the largest group coming from Zimbabwe, for reasons provided earlier. The top Non-SADC country, Nigeria is the fifth overall highest sender and Kenya is the tenth (See Table 2). Furthermore, four of the top non-SADC sending countries are Anglophone and five are Francophone, highlighting the language diversity of these students.

As further demonstrated in Table 3, the top Non-African sending countries are concentrated in the USA and western Europe, with the USA sourcing most and Germany sourcing half of their students as non-degree-seeking students, labeled occasional students. The same holds true for some other western European countries, including France and the 
Table 1 International student enrollment to South Africa by SADC country

Source: Higher education management information system data, (2013), DHET

Table 2 International student enrollment to South Africa by Non-SADC African country

\begin{tabular}{lrrrr}
\hline Nationality & OC & \multicolumn{1}{l}{ UG } & \multicolumn{1}{l}{ PG } & Total \\
\hline Zimbabwe & 507 & 19,720 & 6695 & 26,922 \\
Namibia & 125 & 3561 & 1666 & 5352 \\
Lesotho & 140 & 3299 & 1453 & 4892 \\
Swaziland & 119 & 3045 & 1166 & 4330 \\
Democratic Republic of the Congo & 46 & 2789 & 503 & 3338 \\
Botswana & 93 & 2335 & 703 & 3131 \\
Zambia & 26 & 1171 & 670 & 1867 \\
Angola & 40 & 1047 & 82 & 1169 \\
Malawi & 12 & 461 & 438 & 911 \\
Mauritius & 7 & 543 & 173 & 723 \\
Mozambique & 9 & 341 & 232 & 582 \\
United Republic of Tanzania & 2 & 155 & 293 & 450 \\
Seychelles & 1 & 71 & 12 & 84 \\
Madagascar & 1 & 10 & 38 & 49
\end{tabular}

\begin{tabular}{|c|c|c|c|c|c|}
\hline \multirow{10}{*}{$\begin{array}{l}\text { Table } 2 \text { International student } \\
\text { enrollment to South Africa by } \\
\text { Non-SADC African country }\end{array}$} & Nationality & $\mathrm{OC}$ & UG & PG & Grand total \\
\hline & Nigeria & 66 & 1312 & 2008 & 3386 \\
\hline & Kenya & 26 & 757 & 881 & 1664 \\
\hline & Cameroon & 38 & 563 & 525 & 1126 \\
\hline & Congo & 21 & 726 & 240 & 987 \\
\hline & Ethiopia & 13 & 185 & 740 & 938 \\
\hline & Uganda & 15 & 359 & 469 & 843 \\
\hline & Ghana & 23 & 290 & 458 & 771 \\
\hline & Gabon & 16 & 515 & 91 & 622 \\
\hline & Rwanda & 6 & 187 & 293 & 486 \\
\hline \multirow{2}{*}{$\begin{array}{l}\text { Source: Higher education } \\
\text { management information system } \\
\text { data, (2013), DHET }\end{array}$} & Sudan & 2 & 39 & 149 & 190 \\
\hline & Burundi & 1 & 120 & 38 & 159 \\
\hline
\end{tabular}

Source: Higher education management information system data, (2013), DHET

Netherlands. However, for many of the next highest senders, including the UK, China, and Korea, the majority are postgraduate students (also referred to as graduate students).

Table 4 further shows that South African students constitute the vast majority of students in all types of degree programs, but the distribution of students based on students' geographic origin differ. Whereas $15 \%$ of South African enrollment is at the postgraduate level, a significantly higher proportion of postgraduates are international students, with over half of Other African (Non-SADC) students in postgraduate programs. Furthermore, NonAfrican students are roughly split in each of the three degree categories. Among NonAfrican students, occasional students comprise the highest degree category.

Our analyses also revealed that international students' fields of study were proportionally consistent with local South African students (See Table 5). International students' majors were roughly proportional to those of national students, with a slightly higher proportion of Other African students interested in science, engineering, and technology than other majors. 
Table 3 International student enrollment to South Africa by Non-African country
Source: Higher education management information system data, (2013), DHET

\begin{tabular}{lrrrc}
\hline Nationality & OC & UG & PG & Grand total \\
\hline United States & 918 & 376 & 94 & 1388 \\
Germany & 478 & 267 & 214 & 959 \\
United Kingdom & 22 & 286 & 385 & 693 \\
India & 14 & 245 & 185 & 444 \\
China & 31 & 115 & 183 & 329 \\
Korea & 14 & 64 & 184 & 262 \\
Netherlands & 84 & 72 & 68 & 224 \\
Canada & 35 & 124 & 50 & 209 \\
France & 119 & 40 & 49 & 208 \\
Norway & 102 & 47 & 16 & 165 \\
Iran & 3 & 67 & 30 & 100
\end{tabular}

Table 4 Students degree program by region of origin

\begin{tabular}{lrrrrrrr}
\hline & \multicolumn{2}{c}{ Occasional student } & \multicolumn{2}{c}{ Undergraduate student } & \multicolumn{2}{c}{ Postgraduate student } & Total \\
\hline South African & 19,704 & $2 \%$ & 753,749 & $83 \%$ & 136,386 & $15 \%$ & 909,839 \\
SADC & 1128 & $2 \%$ & 38,548 & $72 \%$ & 14,124 & $26 \%$ & 53,800 \\
Other African & 254 & $2 \%$ & 5371 & $45 \%$ & 6294 & $53 \%$ & 11,919 \\
Non-African & 2040 & $30 \%$ & 2309 & $34 \%$ & 2396 & $36 \%$ & 6745 \\
Total & 23,126 & & 799,977 & & 159,200 & & 982,303 \\
\hline
\end{tabular}

Source: Higher education management information system data, (2013), DHET

Table 5 South African higher education enrollment by geographical origin

\begin{tabular}{lllcl}
\hline Major & South Africa & SADC & Other African & Other country \\
\hline Science, engineering, and technology & 258,655 & 16,458 & 5829 & 2062 \\
Business and commerce & 257,433 & 18,204 & 2609 & 1401 \\
Education, humanities and other & 393,751 & 19,138 & 3482 & 3276 \\
Total & 909,839 & 53,800 & 11,919 & 6738
\end{tabular}

Source: Higher education management information system data, (2013), DHET

While such enrollment information provides various snapshots in student flows, one can only infer that the reasons for seeking a degree are different, depending on one's geography. Less is known, however, from students' direct accounts and the extent to which other factors shape their decisions in choosing South Africa as a regional, continental, or global destination.

\section{Methodology}

Our proposed study sought to answer the following questions: Why do international students choose South Africa? What are the differences based on regional, continental, and global mobility? 
In order to address international students' reasons for mobility toward South Africa, this study utilized both quantitative and qualitative methods to uncover the motivations and aspirations of international students in the country. The research is based on a survey instrument that was previously utilized in the USA (Lee 2008, 2010), Mexico (Cantwell et al. 2009), and South Korea (Jon et al. 2014) and part of a larger study on international students in Africa. The general survey questions included demographic background characteristics (i.e., country of origin, field of study, and degree program); reasons for choosing South Africa and the enrolled institution; educational and career aspirations; perceptions and experiences in the country and institution; and aspirations to stay in the country, return home, or work elsewhere following graduation. The instrument was adapted to the South African context, based on the aforementioned literature, and then further revised based on recommendations from partnering institutional staff and piloted to several international students for additional feedback.

Seven universities participated in the research. The institutions ranged in type, setting, and location. They included each of the three university types (traditional research, comprehensive, and technology universities) and are located in urban and rural settings in the following provinces: Eastern Cape, Gauteng, the Northwest, and Western Cape. In total, 1,682 international students completed the survey.

The research sample varied and reflected the diversity of South Africa's international students. They included $52 \%$ females and $76 \%$ were from the African continent. The remaining were from Europe (8\%), North America (8\%), Asia (4\%), and Other (1\%). The leading countries from outside the continent were the USA (7\%), Germany (2\%), India (1 $\%)$, and the UK (1\%). The participants were approximately $50 \%$ undergraduate degreeseekers, $43 \%$ postgraduate degree-seekers, and $7 \%$ other (short-term, non-degree, etc.) Students' majors also varied and were grouped to compare with the national data. As shown in Table 6, the sample data included an overrepresentation of students from Other African and Non-African regions (and correspondingly, from majors outside the science and business fields), which allowed for better statistical comparisons between the three regional groups.

The study utilized mixed methods as a means to capture both breadth and depth. To broadly address the research questions, descriptive analyses, including a series of Kruskal-

Table 6 Comparing research sample with South African international student national data

\begin{tabular}{|c|c|c|c|c|}
\hline \multirow[t]{2}{*}{ Background } & \multicolumn{2}{|c|}{ Research sample } & \multicolumn{2}{|c|}{ National data of international students } \\
\hline & $N$ & $\%$ of Intl Stu & $N$ & $\%$ of Intl Stu \\
\hline SADC region & 860 & 50 & 53,800 & 75 \\
\hline Other Africa region & 442 & 26 & 11,919 & 16 \\
\hline Non-Africa region & 400 & 24 & 6738 & 9 \\
\hline Science, engineering, technology & 757 & 41 & 24,348 & 34 \\
\hline Business and commerce & 337 & 18 & 22,214 & 31 \\
\hline Education, humanities and other & 758 & 41 & 7338 & 10 \\
\hline Undergraduate & 502 & 50 & 22,814 & 64 \\
\hline Post graduate & 436 & 43 & 46,228 & 31 \\
\hline Occasional student & 76 & 7 & 3422 & 5 \\
\hline
\end{tabular}

National data source: higher education management information system data, (2013), DHET Percentages rounded to the next whole percent 
Wallis tests, were conducted. The Kruskal-Wallis test is a nonparametric test used to compare three or more samples when ANOVA normality assumptions may not apply. The Kruskal-Wallis test compares mean ranks of independent samples and whether they are from the same population. The scores from each group were summed and compared to the scores in the other groups in order to determine statistical differences for each variable of interest. For the variables that show significant differences in the Chi-square tests in the Kruskal-Wallis test, an additional set of analysis was conducted with the Mann-Whitney to ascertain which pairs of the groups differed significantly from one another, with a Bonferroni corrected alpha at .016 (.05/3). The survey question that was examined asked, "When choosing to study in South Africa, how important was each of the reasons listed below..." The question was followed by 12 four-point Likert-scaled reasons for choosing the country, including academic, financial, geographical, cultural, and other rationales, as determined by previous research and previous pilot testing. Each of these reasons was tested for differences by those studying within their home region (SADC), outside their home region but within the same continent (Other African), and outside their home continent (Non-African).

In order to identify possible answers not captured in the predetermined items in survey and allow students to elaborate, we also included an open-ended survey question asking them to further comment on reasons for choosing to study in South Africa. We then applied analytic induction to identify similarities in students' comments and then developed preliminary themes. These themes were then refined and modified upon the rereading and rethinking of the data (Bogden and Bilken 2003; Marshall and Rossman 1999), resulting in the two broad themes and two sub-themes in each, as will be described in the following section.

\section{Findings}

Our survey findings indicated that the leading survey items for choosing South Africa as a study destination were related to career mobility, followed by academic research (See Table 7). Both items were related to the country's role in developing human capital. The next highest responses were related to culture, geographic location, and nearby family or friends. Less commonly reported reasons were learning in English, guidance from teachers, and government funding.

To observe any statistically significant differences in the reasons for students' destination decision by their region of the origin, a series of Kruskal-Wallis tests were conducted. Among the 12 reasons for choosing South Africa as a destination, the extent of these reasons significantly differed across the three regional groups with the exception of oneprofessor, teacher, or counselor recommendation; there were significant differences in each reason by the regions (See Table 8). The reason, proximity of South Africa to the home country, was rated the highest among SADC students, followed by Other African students. Similarly, South Africa's visa process, expecting better jobs with a South African education, having family or friends in the country, political safety and stability, and government funding were rated the highest reasons among students from the region, followed by students from outside the region but within the continent, and then students from outside the continent. Conversely, students from outside the continent valued experiencing the South African culture, getting away from home, improving English language, and lower cost of living as their driving rationales compared to those from within the continent. 
Table 7 Reason for studying in South Africa

\begin{tabular}{|c|c|c|c|c|c|c|}
\hline Reason & $\begin{array}{l}\text { Not } \\
\text { important or } \\
\text { not true }\end{array}$ & $\begin{array}{l}\text { Somewhat } \\
\text { important }\end{array}$ & $\begin{array}{l}\text { Very } \\
\text { important }\end{array}$ & $\begin{array}{l}\text { Most } \\
\text { important }\end{array}$ & $\begin{array}{l}\text { Total } \\
\text { responses }\end{array}$ & Mean \\
\hline $\begin{array}{l}\text { I expect better future jobs with } \\
\text { South African education }\end{array}$ & 394 & 448 & 499 & 339 & 1680 & 2.47 \\
\hline $\begin{array}{l}\text { Opportunity for academic } \\
\text { research in South Africa }\end{array}$ & 410 & 471 & 470 & 322 & 1673 & 2.42 \\
\hline $\begin{array}{l}\text { To experience South African } \\
\text { culture }\end{array}$ & 589 & 553 & 364 & 168 & 1674 & 2.07 \\
\hline $\begin{array}{l}\text { South Africa is located close to } \\
\text { my home country }\end{array}$ & 735 & 417 & 332 & 189 & 1673 & 1.99 \\
\hline $\begin{array}{l}\text { I have family or friends in South } \\
\text { Africa }\end{array}$ & 804 & 379 & 271 & 219 & 1673 & 1.94 \\
\hline $\begin{array}{l}\text { Lower cost of living in South } \\
\text { Africa }\end{array}$ & 910 & 393 & 261 & 109 & 1673 & 1.74 \\
\hline To get away from my home & 982 & 361 & 198 & 133 & 1674 & 1.69 \\
\hline $\begin{array}{l}\text { South Africa has an easier visa } \\
\text { process }\end{array}$ & 958 & 386 & 232 & 94 & 1670 & 1.68 \\
\hline $\begin{array}{l}\text { Political stability and safety } \\
\text { compared to home country }\end{array}$ & 1062 & 286 & 180 & 142 & 1670 & 1.64 \\
\hline $\begin{array}{l}\text { To improve my English language } \\
\text { ability }\end{array}$ & 1175 & 179 & 176 & 142 & 1672 & 1.57 \\
\hline $\begin{array}{l}\text { My professor/teacher/counselor } \\
\text { advised me to study in South } \\
\text { Africa }\end{array}$ & 1111 & 291 & 178 & 89 & 1669 & 1.55 \\
\hline $\begin{array}{l}\text { I received government funds to } \\
\text { study in South Africa }\end{array}$ & 1330 & 73 & 92 & 166 & 1661 & 1.45 \\
\hline
\end{tabular}

For the variables, geographic proximity, easier visa process, future job prospect, to get away from home, and opportunity to academic research, the Mann-Whitney tests did not show any subgroups among the three regions, indicating that students from each region presented distinct scores, students from SADC are the highest, followed by Other African countries, and then Non-African countries present the lowest scores. On the other hand, for experiencing the South African culture and improving English skills, Non-African students rated these items higher, followed by students from the two closer regions (SADC and other African countries) as one homogenous group. Non-African students also prioritized South Africa's lower cost of living, followed by Other African and Non-African students, with no homogeneous subgroups for this item. By contrast, students from Africa (from SADC or other African countries), as a homogenous group, indicated political stability and safety as a more important rationale than students from non-African countries. Finally, students from outside the SADC region (Other Africa and Non-Africa) were a homogenous group that scored lower compared to students from SADC for the reason related to government funding.

What were especially noteworthy were the contextual subsets that emerged when comparing the three groups. Reasons related to better future employment were significantly higher for SADC students, followed by Other African students, and then Non-African students. Geographical and personal factors, location to home country, and having family or friends in the country also varied based on proximity, with SADC students rating these 
Table 8 Kruskal-Wallis test results for reasons for studying in South Africa by home region

\begin{tabular}{|c|c|c|c|c|c|c|c|}
\hline \multirow[t]{2}{*}{ Reason } & \multicolumn{2}{|c|}{ SADC } & \multicolumn{2}{|c|}{ Other Africa } & \multicolumn{2}{|c|}{ Non-Africa } & \multirow[t]{2}{*}{$p$} \\
\hline & $N$ & $\begin{array}{l}\text { Mean } \\
\text { rank }\end{array}$ & $N$ & $\begin{array}{l}\text { Mean } \\
\text { rank }\end{array}$ & $N$ & $\begin{array}{l}\text { Mean } \\
\text { rank }\end{array}$ & \\
\hline South Africa is located close to my home country & 850 & 1095 & 434 & 645 & 390 & 489 & .00 \\
\hline South Africa has an easier visa process & 845 & 947 & 435 & 781 & 391 & 654 & .00 \\
\hline $\begin{array}{l}\text { I expect better future jobs with South African } \\
\text { education }\end{array}$ & 853 & 952 & 438 & 870 & 390 & 563 & .00 \\
\hline To experience South African culture & 848 & 723 & 435 & 758 & 391 & 1172 & .00 \\
\hline To improve my English language ability & 847 & 790 & 435 & 838 & 391 & 937 & .00 \\
\hline To get away from my home & 850 & 810 & 435 & 738 & 391 & 1010 & .00 \\
\hline Opportunity for academic research in South Africa & 850 & 837 & 434 & 927 & 390 & 736 & .00 \\
\hline $\begin{array}{l}\text { My professor/teacher/counselor advised me to } \\
\text { study in South Africa }\end{array}$ & 846 & 837 & 434 & 859 & 390 & 803 & .12 \\
\hline I have family or friends in South Africa & 850 & 916 & 434 & 791 & 390 & 717 & .00 \\
\hline $\begin{array}{l}\text { Political stability and safety compared to home } \\
\text { country }\end{array}$ & 848 & 896 & 432 & 876 & 392 & 661 & .00 \\
\hline Lower cost of living in South Africa & 848 & 830 & 436 & 676 & 390 & 1031 & .00 \\
\hline $\begin{array}{l}\text { I received government funds to study in South } \\
\text { Africa }\end{array}$ & 838 & 856 & 435 & 807 & 389 & 804 & .00 \\
\hline
\end{tabular}

items the highest, Non-Africans rating these the lowest, and Other Africans in the middle. Other regional factors influenced SADC students to study in the country, including an easier visa process and government funds, which reflect elements of the SADC Protocol that facilitate regional mobility. For Non-Africans, their rationales were much different. They were most motivated by opportunities to experience the South African culture, improve their English language ability, get away from home, and get drawn to its lower cost of living. As demonstrated, the rationales for regional mobility to South Africa were related to future employment, location and personal relationships, and regional agreements, which were not as highly rated for students from outside the region, least of all for NonAfricans.

While the survey results provide an overview of relative importance, students' comments provided further details on choosing this country to study. Analyses of the qualitative data resulted in the following emergent themes: human Capital, which included employment/economic reasons and academic reasons, and geopolitics, which was subdivided into security/political reasons and sociocultural reasons. While these categories are presented separately as a means to organize and group common responses, we also found some overlap as many of these rationales were interrelated, as will be shown. We also uncovered similar patterns as in the quantitative findings by region of origin.

Human capital

\section{Employment and economic reasons}

Consistent with the survey results that the highest ranked reason for the choice of South Africa as a destination of study was an expectation to be more competitive in the job 
market, this rationale was commonly reported and elaborated on in the open-ended survey questions. There was a strong consensus among the African participants that the acquisition of international qualifications would enhance their job mobility. This view, however, was markedly absent from the non-Africans.

Because of the quality of education they expected to receive in South Africa, the African respondents anticipated being able to secure better future employment opportu-nities in South Africa and elsewhere than if they remained at home. The following excerpts exemplified this sentiment:

- They have better schools than my home country, and a degree from [name of university] would help my chances of getting a proper paying job. (Nigeria)

- Higher chance of securing a job in South Africa than in my home country where there basically isn't a job market for my degree once I graduate. (Zimbabwe)

- South African degrees are recognized worldwide at a much lower price as compared to most other famous universities around the world. Furthermore, jobs will not be much of a problem to obtain. (Mauritius)

As shown, African students repeatedly stated the significance of a South African degree in comparison with options in their home countries. This view is perhaps best summarized by a Malawian student: "South Africa is seen as Africa's "America', as well and having a recognized degree from one of its institutions will most likely open doors around Africa when it comes to getting a job.' As exemplified by this quote, there was clear awareness among some participants on the reputation of a US degree, but South Africa was generally understood as the top destination within the continent.

For some Africans outside the SADC, continental mobility was a stepping-stone toward global mobility. According to a student from Cameroon, "Because of [name of university's] education, [which] can help me to find a better and suitable job in Europe Asia or USA." Others similarly expressed future plans to pursue a job or graduate degree outside the continent and that a South African education would provide the necessary preparation toward such goals. As stated by a student from the Democratic Republic of Congo, "The level of education is high and it is easy to get a job around the world with a South African degree."

However, South Africa's value in promoting upward mobility was not completely exclusive to African students. According to an Indian student, "It's an emerging market and lots of opportunities will be there in future. This is the number one MBA institute in Africa. Being from India, it gives me the opportunity to explore one of the BRICS nations and I will be in the position to do a job where foreign trade between India and South Africa is there." In summary, participants believed that attending universities in South Africa would open prospects for more job opportunities, but these views were largely concentrated among the African respondents.

In addition to future employment prospects, students also had short-term economic rationales. The analysis of the open-ended survey data revealed that the economic factor can be subdivided by home region. On one hand, African students mentioned affordability in terms of tuition fees and cost of living as compared to other countries in the world. As expressed by a student from Uganda, "I could not afford fees in Europe and America but sought to find the best education I could get on the African continent and that's why I chose South Africa." For SADC students in particular, the regional agreement made tuition comparable to studying at home, thus making tuition fees more affordable for them than elsewhere. A student from Zimbabwe explained, "It was the cheapest education of high standard my parents could afford." For non-African students, the cost of tuition and living 
was relatively low, particularly in light of South Africa's depreciating currency. According a student from the UK, "I had the opportunity to do my masters at a top university [name of university] for half the price it would have cost back home (UK), which was a main motivating factor.",

Another important factor related to finances was the proximity to the home country. A number of SADC students mentioned closeness to their home countries as well as living costs as reasons as to why they chose to study in South Africa. One Zimbabwean student explained, "I chose to study in South Africa because my guardian who is my mother has been here in South Africa for more than 6 years. The distance between us prompted me to get closer to where she was for easy access of resources.' Another Zimbabwean student commented, "It was easy to adapt since it is close to my country and our cultures are somewhat similar." This view is supported by the fact that four of the major sending countries to South Africa share national borders with South Africa (Lesotho, Zimbabwe, Namibia, and Botswana). As a result of the artificial colonial boundaries, citizens across these national borders would share similar languages, dress codes, as well as weather conditions, which would make it easy for students from these countries to adapt to the host environment.

\section{Academic reasons}

South Africa's reputable higher education programs are also mentioned extensively in the survey comments. This view was especially pervasive among the African respondents. For example, one participant from the Democratic Republic of Congo indicated, "I chose to study in South Africa because it is one of the developed countries in Africa and its level of education is respected all around the world." A Nigerian participant similarly commented, "Quality of education is comparable with that obtained anywhere in Europe or western countries." The lack of specific or suitable courses of study was mentioned as another reason that motivated African students especially to choose to study in South Africa. One participant reported, "I have always wanted to study Dentistry and unfortunately that is not offered at the university in my country, Namibia. Therefore I had to seek other opportunities abroad and I am thankful for my acceptance at [name of university]." Another finding linked to academics is the fact that some participants wanted to diversify their educational experiences and qualifications, and South Africa seemed to be a suitable destination. For example, one respondent from Botswana indicated, "I did my first degree in my home country, second degree in Europe, I wanted to have another degree in an African country apart from my home country and South Africa is ideal to expose me to different African cultures.' Such views were shared about Non-African students as well, as exemplified by this comment from a German student, "I chose to come here because: (1)[name of university] has a great reputation for research in sports science. (2) It is a widely acclaimed institution. (3) The research was exciting."

Geopolitical reasons

\section{Security and political reasons}

African higher education has historically experienced considerable unrests caused mainly by students as well as staff dissatisfaction. Such disruption, in turn, would affect the normal functioning of higher education institutions including delaying the beginning of academic year or frequent campus closings. The survey comments further revealed the relative 
stability of South Africa as a reason for African students to choose to pursue their studies in South Africa than in their home countries. In this regard, one participant from Malawi noted, "It was an alternative plan for me after seeing the academic instability that was currently reigning in my country at the time." Another participant mentioned stability in the educational system as the main reasons that motivated the decision to study in South Africa. In particular, a participant from Nigeria wrote, "Academics don't usually embark on industrial action to settle their disputes with South Africa government."'

The survey comments further revealed that some African students were studying in South Africa because of a lack of security, peace, and stability in their home countries. While on the one hand political instability in their countries acted as a push factor, on the other hand, political stability in South Africa acted as a pull factor. The following comments exemplified such sentiments:

- I was already living in the Republic of South Africa as a refugee. (Uganda)

- I am a Rwandan refugee who fled the country [because of] political instability, human rights abuse, and insecurity. I became a student as an alternative for life. (Rwanda)

- Because I have no choice as my life as well as for my children was in danger for political reason. (Democratic Republic of Congo)

This finding is consistent with the South African government's efforts to permit students from SADC countries earlier access to higher education in South Africa. For some, the process of obtaining visas was quite flexible as captured from one of the participants who wrote, "For me it was easy to come because they waived the visa requirements for Zimbabweans." This sentiment held particularly true for students from other SADC countries.

\section{Social and cultural reasons}

Students from all regions indicated a range of social and cultural factors that motivated international students to study in South Africa. In particular, for numerous students from outside the continent, their parents' or partners' employment influenced their decision to enroll in South Africa. A Canadian wrote "My husband had a job opportunity in [name of city] and I was able to start grad school at [name of university], and that is the main reason for choosing SA." For some, studying in South Africa was more of a matter of circumstances than their top ambition. A participant from the USA noted, "My husband is from South Africa and we decided to stay in South Africa. I had wanted pursue a masters in the US but those plans changed when we decided to stay in SA... Honestly, as something to fill my time as I got used to living in South Africa.' Another participant from Norway gave a similar reason pointing that "Because my dad got a job here. I would've gone abroad in any case, but somewhere closer to home like France for instance."

In addition to familial connections, there were students across the different regions who were interested in studying in the English language and learning about the African or South African culture. For students from Francophone countries in west Africa, studying in South Africa was a viable option while remaining in the continent. For example, a student from Cote d'Ivorie indicated, "I chose to study in South Africa firstly because of the language, I wanted to speak more than one language as I already have French for first language.' In addition, numerous students from different regions were drawn to South African history and culture. A student from the Netherlands wrote, "I am interested in studying the apartheid and how it still affects South Africa. How big the impact can be and how long the effects will last.' In some cases, South Africa was depicted as representative of the larger 
continent. According to a student from Malawi, "University offered a course that I wanted to study and was within the African continent. I wanted to study the course at an institution that would have a true representation of African poverty unlike if I was to study the course in Europe."'

\section{Discussion}

International mobility is at an all-time high with increasing numbers of students opting to study within their regions. Included in this phenomenon are international students studying in emerging economies, which will likely be the primary players in regional mobility. This research investigated this significant aspect of international mobility using the case of South Africa. Furthermore, this study also introduced an intermediary gap between re-gional mobility and global mobility, which we termed as continental mobility.

Findings indicate distinct differences in students' reasons for studying in South Africa across regional, continental, and global mobility patterns. For SADC students, regional cooperation efforts, which included governmental policies and financial incentives, were key draws. And for most SADC and other African students, South Africa offered quality higher education that surpassed what was available or accessible in their home countries while staying within the continent. An international education in South Africa was also perceived as an opportunity to enhance African students' job competitiveness. Such findings confirm South Africa's role in building human capital within the region as well as the continent. For a minority of African students further indicated being close to family was also a major draw, and for some Africans outside the SADC region, South Africa offered immediate political safety and educational stability. In sum, the quality, afford-ability, location, social connections, and stability explain the popularity of South Africa as a regional and continental hub.

Findings also show how South Africa serves as also a global destination, albeit for a much smaller proportion of the world's students outside the continent. Like students from Africa, non-African students, mostly from the USA and western Europe, were also drawn to the location, but for a very different set of rationales. These students tended to be nondegree seekers or opted to study in the country after obtaining their undergraduate degrees elsewhere. Non-Africans viewed the location as attractive, but for opposite reasons that were related to getting away from home and experiencing a culture unlike their own. Unlike Africans, who tended view studying in the country as a means toward job competitiveness or seeking a quality education not available at home, the non-Africans in this study were more interested in the affordability of studying the African culture and in several cases, a matter of familial circumstances with family members already in the area.

We offer several implications for South African universities in differentiating the large pool of international students who seek to study in South Africa. First, the country's primary group of international students, those from the SADC, are most likely to build upon the economic competitiveness of region. They are most driven by human capital development compared to outside regions and are presumably most likely to stay in the region given their rationale related to South Africa's proximity to home. From a national and regional development perspective, SADC students would more likely stay. In terms of direct capacity building within the continent, African international students rated opportunities for academic research in South African universities higher than non-Africans. These continentally mobile students are likely greater potential sources of research output and income generation for universities as many of these students come particularly for its 
graduate programs. South Africa's top universities would especially benefit from such international students in order to strengthen their research capacity and global competitiveness. Second, international students from outside the SADC region are more likely selffinanced from their home governments or private funds and, in some institutions, charged double the amount of fees compared to South African and SADC students. In this way, international students from outside the SADC have become a source of additional revenue. This is particularly true for those who study on a full-time basis, as they tend to complete their studies faster than national students and therefore contribute to further subsidy income. Thus, the immediate financial benefits of such students for institutions should be weighed in light of national and regional development goals. Finally, despite the immediate financial benefits, questions remain on the extent to which international students may be occupying places that could be filled by national students, given the high demand for higher education, especially at the country's top universities. On the one hand, the international students contribute to the internationalization of these campuses, which can benefit local students by exposing them to international perspectives without leaving national borders. On the other hand, those from outside the continent tend to be occasional students who are less interested in studying in the country as a stepping-stone for upward mobility or capacity building and more interested getting away from their homes and its relatively low cost of living. The extent to which spaces should be allocated for such students should also be weighed.

In closing, international student mobility is hardly a unidirectional phenomenon based on a uniform set of rationales. It is also not a random assortment of individual choices. As this study revealed, regional agreements matter and the perceived quality of an institution is relative, based on what is available at home. It is also quite unlikely that emerging economies will become major global destinations. At best, they will serve as active regional and continental hubs, drawing students within the immediate area seeking a higher quality level of education or international exposure. With the exception of a few very highly ranked research universities, the international role of universities in emerging economies, such as South Africa, are in regional, and sometimes continental, development. This mission is in stark contrast to the top global destination, the USA, which prepares mostly Asian students (i.e., China, Korea, and India) (IIE 2013). The extent to which South Africa and other universities in emerging economies seek to become top global destinations is unknown, but as this study has demonstrated, might come at the expense of their regional role.

\section{References}

Altbach, P. G. (2004). Higher education crosses borders. Change, 36(2), 18-24.

Bhorat, H., Meyer, J., \& Mlatsheni, C. (2002). Skilled labor migration from developing countries: Study on south and southern Africa. Geneva: International Migration Programme, International Labour Office.

Bogden, R. C., \& Bilken, S. K. (2003). Qualitative research in education: An introduction to theories and methods (4th ed.). New York: Allen and Bacon.

British Council. (2012). The shape of things to come: Higher education global trends and emerging oppottunities to 2020. Going Global 2012 Report. Retreived from http://www.britishcouncil.org/sites/ britishcouncil.uk2/files/the_shape_of_things_to_come_-_higher_education_global_trends_and_emerging opportunities_to_2020.pdf

Cantwell, B., Luca, G. C., \& Lee, J. J. (2009). Exploring the orientations of international students in Mexico: Differences by region of origin. Higher Education, 57, 335-354.

Chien, C., \& Kot, F. C. (2011). Building regional higher education capacity through academic mobility. Southern African Regional Universities Association. 
Crush, J., Williams, V., \& Peberdy, S. (2005). Migration in Southern Africa. In Policy analysis and research programme of the global commission on international Migration, Cape Town.

Ghemawat, P., \& Altman, S. A. (2014). DHL global connectedness index 2014.

Institute of International Education. (2013). Open doors data: Fast facts. Retrieved from http://www.iie.org/ en/Research-and-Publications/Open-Doors/Data/Fast-Facts

Jon, J. E., Lee, J. J., \& Byun, K. (2014). The emergence of a regional hub: Comparing international student choices and experiences in South Korea. Higher Education, 67(5), 691-710.

Kiboiy, K. L. (2013). The dynamics of student unrests in Kenya's higher education: The case of Moi University. A thesis submitted to the Department of Education Management and Policy Studies, University of Pretoria in fulfilment of the requirements of the degree of Doctor of Philosophy, Pretoria, University of Pretoria.

Kondakci, Y. (2011). Student mobility reviewed: Attraction and satisfaction of international students in Turkey. Higher Education, 62, 573-592.

Lee, J. J. (2008). Beyond borders: International student pathways to the U.S. Journal of Studies in International Education, 12(3), 308-327.

Lee, J. J. (2010). International students' experiences and attitudes at a US host institution: Self-reports and future recommendations. Journal of Research in International Education, 9(1), 66-84.

Lee, J. J., \& Kim, D. (2010). Brain gain or brain circulation? U.S. doctoral recipients returning to South Korea. Higher Education, 59(5), 627-643.

Li, M., \& Bray, M. (2007). Cross-border flows of students for higher education: Push- pull factors and motivations of Mainland Chinese students in Hong Kong and Macau. Higher Education, 53(6), 791-818.

MacGregor, K. (2007). South Africa: Huge growth in foreign students. University World News. Retrieved from http://www.universityworldnews.com/article.php?story=20071206163532421\&mode=print

Marko, K. (2009). Internationalization of higher education in Southern Africa with South Africa as the major exporter. Trade and Industrial Policy Studies: Services Sector Development and Impact on Poverty Thematic Working Group.

Marshall, C., \& Rossman, G. B. (1999). Designing qualitative research (3rd ed.). Thousand Oaks, CA: Sage.

McMahon, M. E. (1992). Higher education in a world market. An historical look at the global context of international study. Higher Education, 24(4), 465-482.

Nkinyangi, J. A. (1991). Student protests in sub-Saharan Africa. Higher Education, 22, 157-173.

Organisation of Economic Cooperation and Development. (2014). Education at a glance, 2014. Paris: OECD.

SAccess. (2014). Supporting the EU access to South Africa's research and innovation programmes. ACCESS4EU: South Africa (Contract Number 243851). Retrieved from: http://www.esastap.org.za/ download/sa_ri_capacity.pdf

Sehoole, C. (2011). Student mobility and doctoral education in South Africa. Perspectives in Education, 29(3), 53-63.

United Nations Educational Scientific and Cultural Organization (UNESCO). (2012). New Patterns in Student Mobility in the Southern Africa Development Community. UIS Information Bulletin. United Nations Educational, Scientific and Cultural Organization (UNESCO). 7.

World Economic Forum. (2014a). The global competitiveness report 2014-2015. http://reports.weforum. org/global-competitiveness-report-2014-2015/

World Economic Forum. (2014b). The global competitiveness report 2014-2015: Country/economy highlights http://www3.weforum.org/docs/GCR2014-15/GCR_Highlights_2014-2015.pdf 